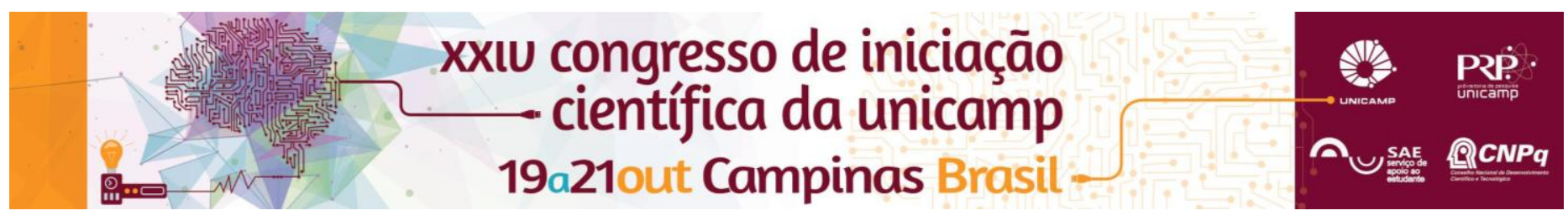

\title{
Impacto de diferentes métodos de inativação sobre a eficácia de micro-organismos probióticos
}

\author{
Mariane S. Bonatto, Caroline N. de Almada, Carine N. de Almada, Anderson S. Sant'Ana (DCA/FEA/UNICAMP).
}

\section{Resumo}

Os probióticos são micro-organismos vivos que quando ingeridos em quantidades e frequências adequadas podem proporcionar benefícios à saúde do hospedeiro. Nos últimos anos tem-se reportado o potencial de micro-organismos probióticos inativados em também proporcionar benefícios à saúde. Porém, o método de inativação pode impactar sobre a capacidade do micro-organismo inativado em conferir benefícios aos hospedeiros.

\section{Palavras-chave:}

Bifidobacterium, Lactobacillus, métodos de inativação.

\section{Introdução}

Vários tipos de micro-organismos, principalmente bactérias e leveduras, têm sido reportados com atividade probiótica e alguns aplicados em alimentos e clínica. Os principais gêneros utilizados como probióticos são Lactobacillus, Bifidobacterium, Streptococcus, Leuconostoc, Pediococcus, Propionibacterium, Bacillus, Enterococcus e Saccharomyces (AMARA \& SHIBL, 2013).

Vários métodos podem ser utilizados para inativar os micro-organismos probióticos objetivando-se sua aplicação posterior como suplemento, dentre os quais destacam-se tratamento por alta pressão, acidez, calor, ultravioleta, secagem e irradiação. Sugere-se que o método de inativação pode impactar na eficácia dos probióticos inativados sobre seus efeitos benéficos aos hospedeiros (RAZ \& RACHMILEWITZ, 2005).

Assim, tratamentos em intensidades que resultem na inativação dos probióticos, mas que garantam a integridade das células deste microorganismo e a segurança e estabilidade microbiológica dos alimentos constituiriam-se boas opções de sua veiculação. Desta forma, tal abordagem vai de encontro ao desejo dos consumidores de adquirirem alimentos menos processados e mais próximos aos naturais (ZINK, 1997, RAGAERT et. al., 2004).

Dessa forma, os objetivos desse trabalho basearam-se em estudar e caracterizar diversos métodos de inativação (tratamento térmico, ultrassom, redução e aumento do $\mathrm{pH}$, irradiação e $\mathrm{CO}_{2}$ supercrítico) de microorganismos probióticos.

\section{Resultados e Discussão}

A inativação foi realizada com Lactobacillus casei 01 e Bifidobacterium animalis bb12. Os micro-organismos foram então inativados por tratamento térmico, ultrassom, redução e aumento de $\mathrm{pH}$, irradiação e $\mathrm{CO}_{2}$ supercrítico.

A citometria de fluxo foi utilizada para observar atividade enzimática intramolecular e integridade da membrana de micro-organismos submetidos aos métodos de inativação.

Os resultados das análises estão nas tabelas 1 e 2 que se referem respectivamente a Lactobacillus e Bifidobacterium.
Tabela 1. Inativação de Lactobacillus casei 01.

\begin{tabular}{|c|c|c|c|c|c|c|}
\hline & $\begin{array}{l}\text { Tratamento } \\
\text { térmico }\end{array}$ & $\begin{array}{c}\mathrm{pH} \\
\text { baixo }\end{array}$ & $\begin{array}{l}\mathrm{pH} \\
\text { alto }\end{array}$ & $\mathrm{CO}_{2}$ & $\begin{array}{l}\text { Irradi- } \\
\text { ação }\end{array}$ & $\begin{array}{c}\text { Ultras- } \\
\text { som }\end{array}$ \\
\hline $\begin{array}{l}\text { Condições } \\
\text { ótimas de } \\
\text { inativação }\end{array}$ & $\begin{array}{c}80^{\circ} \mathrm{C} / 10 \\
\min \end{array}$ & $\mathrm{ph} 1 / 1 \mathrm{~h}$ & $\begin{array}{c}\mathrm{ph} \\
12,75 / \\
1 \mathrm{~h} 20 \\
\min \end{array}$ & $\begin{array}{l}40^{\circ} \mathrm{C} / \\
30 \mathrm{MP} \\
\text { a/ } 2 \mathrm{~h}\end{array}$ & $3 \mathrm{Kgy}$ & $\begin{array}{l}792 \mathrm{~W} / \\
20 \mathrm{~Hz} / \\
40 \mathrm{~min}\end{array}$ \\
\hline $\begin{array}{c}\text { Integridade } \\
\text { da } \\
\text { membrana }\end{array}$ & Integra & $\begin{array}{l}\text { não } \\
\text { integra } \\
(87 \%)\end{array}$ & $\begin{array}{l}\text { não } \\
\text { integra } \\
(73 \%)\end{array}$ & $\begin{array}{l}\text { não } \\
\text { integra } \\
(95 \%)\end{array}$ & $\begin{array}{l}\text { não } \\
\text { integra } \\
(79 \%)\end{array}$ & Integra \\
\hline $\begin{array}{l}\text { Atividade } \\
\text { enzimática }\end{array}$ & $\begin{array}{l}\text { Com } \\
\text { atividade } \\
(46 \%)\end{array}$ & $\begin{array}{l}\text { Sem } \\
\text { atividade }\end{array}$ & $\begin{array}{l}\text { Sem } \\
\text { ativida } \\
\text { de }\end{array}$ & $\begin{array}{l}\text { Sem } \\
\text { ativida } \\
\text { de }\end{array}$ & $\begin{array}{l}\text { Sem } \\
\text { ativida } \\
\text { de }\end{array}$ & $\begin{array}{l}\text { Com } \\
\text { atividade } \\
(57 \%)\end{array}$ \\
\hline
\end{tabular}

Tabela 2. Inativação de Bifidobacterium animalis bb12.

\begin{tabular}{|c|c|c|c|c|c|c|}
\hline & $\begin{array}{c}\text { Tratamento } \\
\text { térmico }\end{array}$ & pH baixo & $\mathrm{pH}$ alto & $\mathrm{CO}_{2}$ & $\begin{array}{l}\text { Irradia- } \\
\text { ção }\end{array}$ & $\begin{array}{c}\text { Ultras- } \\
\text { som }\end{array}$ \\
\hline $\begin{array}{l}\text { Condições } \\
\text { ótimas de } \\
\text { inativação }\end{array}$ & $\begin{array}{c}80^{\circ} \mathrm{C} / 10 \\
\min \end{array}$ & $\mathrm{ph} 1 / 1 \mathrm{~h}$ & $\begin{array}{c}\text { ph } \\
12,5 / \\
1 \mathrm{~h}\end{array}$ & $\begin{array}{l}40^{\circ} \mathrm{C} / \\
10 \mathrm{MP} \\
\mathrm{a} / 3 \mathrm{~h}\end{array}$ & $\begin{array}{l}2,5 \\
\text { Kgy }\end{array}$ & $\begin{array}{l}792 \mathrm{~W} / \\
20 \mathrm{~Hz} / \\
30 \mathrm{~min}\end{array}$ \\
\hline $\begin{array}{l}\text { Integridade } \\
\text { da } \\
\text { membrana }\end{array}$ & Integra & $\begin{array}{l}\text { não } \\
\text { integra } \\
(13 \%)\end{array}$ & $\begin{array}{l}\text { não } \\
\text { integra } \\
(1,4 \%)\end{array}$ & $\begin{array}{l}\text { não } \\
\text { integra } \\
(58 \%)\end{array}$ & $\begin{array}{l}\text { não } \\
\text { integra } \\
(44 \%)\end{array}$ & $\begin{array}{l}\text { Não } \\
\text { Integra } \\
(4 \%)\end{array}$ \\
\hline $\begin{array}{l}\text { Atividade } \\
\text { enzimática }\end{array}$ & $\begin{array}{l}\text { Com } \\
\text { atividade } \\
(75 \%)\end{array}$ & $\begin{array}{l}\text { Sem } \\
\text { atividade }\end{array}$ & $\begin{array}{l}\text { Sem } \\
\text { ativida } \\
\text { de }\end{array}$ & $\begin{array}{l}\text { Sem } \\
\text { ativida } \\
\text { de }\end{array}$ & $\begin{array}{l}\text { Sem } \\
\text { ativida } \\
\text { de }\end{array}$ & $\begin{array}{l}\text { Com } \\
\text { pouca } \\
\text { atividade } \\
(0,22 \%)\end{array}$ \\
\hline
\end{tabular}

\section{Conclusões}

Os melhores métodos para a inativação de Lactobacillus casei 01 foram por tratamento térmico e ultrassom, uma vez que ambos conferiram uma membrana íntegra e a manutenção da atividade enzimática do probiótico. Todos os outros métodos de inativação levaram à ruptura da membrana e à perda da atividade enzimática.

No caso da inativação do Bifidobacterium animalis bb12 o melhor método foi por inativação térmica. Os demais métodos apresentaram membrana não integra com pouca ou sem atividade enzimática.

\section{Agradecimentos}

Agradeço à MSc. Caroline Nunes de Almada e ao professor Dr. Anderson de Sousa Sant'Ana pelo suporte e dedicação durante todo o projeto.

AMARA, A.A.; SHILB. A. Role of probiotics in health improvement, infection control and disease treatment and management. Saudi Pharmaceutical Journal, 2013.

RAZ, EVAL; RACHMILEWITZ, DANIEL. Inactivated probiotic bacteria and methods of use thereof. Patente n. US20050180962 A1, 18 ago. 2005.

ZINK, D. L. The impact of consumer demands and trends on food processing. Emerging infectious diseases, v. 3, p. 467-469, 1997.

RAGAERT, P.; VERBEKE, W.; DEVLIEGHERE, F.; DEBEVERE, J. Consumer perception and choice of minimally processed vegetables and packaged fruits. Food Quality and Preference, v. 15, p. 259-270, 2004. 